\title{
Cities \& International Policy Diffusion: The Case of Tokyo
}

\author{
Nikita Chiu \\ Centre for Asia-Pacific Studies, \\ Tallinn University of Technology \\ Akadeemia tee 3 , \\ Tallinn 12618, Estonia \\ E-mail: sze.chiu@graduateinstitute.ch
}

\begin{abstract}
In an increasingly globalised world, today's international challenges such as climate change transcend national boundaries and require multi-level governance responses. Cities, in particular, stand out as an essential governing unit with huge potentials in resolving some of the 21st century's most pressing concerns. The recent explosion of the phenomenon of city-networks reflects intensifying city-to-city interactions in addressing global environmental issues. This article examines the case of Tokyo in addressing challenges posed by climate change. Examining the origin, development, and diffusion of Tokyo's climate change policy, the cap-and-trade scheme was found to have first diffused from Europe to Tokyo, adjusted to adapt to the local context, then further diffused to other Asian cities. Study of Tokyo's experience demonstrates that policy formation does not always follow a centralized, top-down, command-and-control approach. This findings challenge conventional realist conception which emphasises the dominance of central authorities and sovereign states in global policy formation. Under the framework of global governance, this article argues that cities are important sites of policy experimentation and innovation, and that the case of Tokyo demonstrates the potential of cross-country policy diffusion.
\end{abstract}

Keywords: cities, climate change, environmental governance, global governance, Tokyo 


\section{Introduction}

For decades, states have been considered the dominant unit of analysis in the discipline of International Relations (IR). During the two world wars and the subsequent Cold War, state leaders and IR scholars were driven to find an end to continuous inter-state conflicts in order to establish international peace and stability. Since the United Nations (UN) was established, the emphasis of debates in the IR discipline has been on engaging sovereign entities. However, the $21 \mathrm{st}$ century has seen a shift of focus: the world now faces numerous global problems that do not end at national borders. The international community has thus moved its concerns from inter-state conflicts to efforts in tackling challenges posed by a series of transnational problems that require international responses. Global challenges such as the spread of infectious diseases, climate change, nuclear security, and human and drug trafficking demand not only effective inter-state cooperation, but also active engagement of state, sub-state, and non-state actors.

Conventional IR theorists understand states to be the sole relevant actors in resolving international problems. Governance is understood to be hierarchical, with treaties agreed at the international level, translated into national policies, and duly executed at the local level by sub-state authorities such as cities. There is growing evidence, however, that demonstrates otherwise. The academic community began recognising the role that is played by non-state actors such as non-governmental organisations (NGOs) and multinational corporations in contributing to global governance in the area of human rights, environmental protection and poverty reduction (Keck \& Sikkink, 1998; Ruggie, 2001). In recent years, however, cities also attract mounting attention from scholars and policymakers. In the environmental domain, cities are now recognised as a pertinent actor in adapting to and mitigating the effects of climate change (Betsill \& Harriet, 2003; 2004; 2006). In contrast to the reluctance of major powers such as the US and China in introducing a universally binding reduction quota, cities often stand out as having a more ambitious carbon reduction policy. Gradually but convincingly, cities have emerged as important actors in the fight against climate change.

This contribution argues that cities are relevant and important actors in global environmental governance. Using cases in the Asia-Pacific as indicative examples, it will highlight cities' leadership in the environmental domain. This research shows that cities play a crucial role in filling the governance gap in climate policy, contributing to global carbon reduction in the absence of adequate state intervention. The article further argues that the concentration of population, services and capitals put cities at a distinctive advantage in policy 
experimentation and innovation. Cities that enjoy extensive connectedness with the outside world — what Saskia Sassen (1991) defines as global cities-are particularly apt to serve as hubs of exchange of ideas, and in turn, facilitate policy diffusion. This article concludes that states should look to engage cities in order to enhance the effectiveness of their efforts in combating climate change.

\section{Limits of the state-centric environmental governance mechanism}

Although the topic of climate change has recently dominated discussions in international fora, intergovernmental mechanisms for curbing carbon emission are in fact relatively weak when compared with other more institutionalised regimes (e.g., HIV/AIDS and other infectious diseases regimes, the International Atomic Energy Agency, IAEA, in monitoring civilian nuclear facilities). Until the Paris Agreement, a universally binding climate change deal has failed to emerge despite multiple rounds of negotiations. This article paid particular focus on the period from late 2000 s to early 2010 s, examining the dynamic policy landscape at a time when multiple levels of governance units (i.e., national governments, cities, local authorities) strive to address climate change by launching a variety of initiatives.

Cities have long been vocal in asserting the importance of tackling climate change. Even before the Paris Agreement and the emergence of the international consensus on pursuing Agenda 2030 - the UN Sustainable Development Goals - cities have publicly pledged to ambitious reduction quotas at the Mayoral Summit in Copenhagen in 2010. In contrast, numerous major state actors showed a lack of commitment to a binding quota, and at times showed shifting stances in response to the call of carbon reduction. For example, the US - one of the largest carbon emitters in the world - for a long time remained outside of obligations imposed by the Kyoto Protocol. Although the US is currently bound by the Paris Agreement due to the Agreement's exit process, the incumbent administration had already publicly announced the intention to withdraw from the Agreement. (Mooney, 2018) Another example would be Canada. An influential player during the negotiation period of the Kyoto Protocol, Canada had earlier withdrawn from the Protocol in 2011. The decision came after Ottawa failed to meet her reduction commitments.

In spite of the conclusion of the Paris Accord, the climate change regime is still considered comparatively weak in terms of institutionalisation when compared to other more established international governance mechanisms (e.g., WTO, 
IAEA). The climate change regime is yet to witness the emergence of a permanent dedicated agency with a strong verification or compliance monitoring mechanism. A secretariat to the UN Framework Convention on Climate Change (UNFCCC) was indeed established; however, the secretariat's core tasks remain mainly to co-ordinate organisation of conventions under the framework, assist in reviewing reports submitted by states, and maintain the registry for Nationally Determined Contributions (NDC).

During the focused period examined (late 2000s to early 2010s), there was considerable variance in terms of reduction goals among regions. In the European Union (EU), Brussels passed a climate directive, which seeks to reduce $20 \%$ of greenhouse gas (GHG) emission by increasing the use of renewable technology by $20 \%$ by 2020 . These practices of setting explicit reduction targets remain regionally confined. In fact, it appears that states at the time were moving away from legally binding reduction commitments towards voluntary, non-binding goals. For example, after Canada's withdrawal from the Kyoto Protocol, Ottawa opted to join the Copenhagen Accord, a non-binding agreement that does not specify a universal reduction target. Furthermore, Russia, New Zealand and Japan decided against extending their commitments for the second commitment period (2013-2020) of the Protocol (Arsenault, 2012; Carrington \& Vaughan, 2011).

More recently, the latest conclusion of the Paris Agreement did not entail a binding quota of reduction. Instead, parties to the Agreement are requested to prepare and communicate Nationally Determined Contributions (NDCs) that they seek to achieve. (Paris Agreement, Art. 4, para. 2, 2015)

\section{Global cities and global environmental governance: the case of Tokyo}

The inadequacy of states' contribution to tackling climate change has created space for cities to lead the global effort of reducing greenhouse gas (GHG) emissions. In the US, where the Kyoto Protocol was not ratified, progressive cities formed an alliance and declared that they would bypass national reservation, and directly uphold or surpass the reduction targets set out in the Kyoto Protocol in 2018 (US Conference of Mayors Climate Protection Agreement, 2008). Similar efforts can also be found across the Asia-Pacific region, where cities became the sites for more progressive policies that drive innovation in sustainable policy and contributed greatly to the reduction of carbon emissions. Global cities, in 
particular, lead the international carbon reduction effort in spite of previous stalemate at inter-state negotiations.

Based on research on New York, London and Tokyo, Saskia Sassen, the winner of the Prince of Asturias Award in Social Sciences in 2013, defines global cities as

sites for (1) the production of specialised services needed by complex organisations for running a spatially dispersed network of factories, offices, and service outlets; and (2) the production of financial innovations and the making of market, both central to the internationalisation and expansion of the financial industry. (Sassen, 1991, p. 5)

Cities are where flow of capital, information, and human resources occur. As such, cities occupy key positions in the international economic network (Sassen, 1991). Emphasising cities' crucial economic role in the global economy, Peter Taylor shares similar understanding of the term. In 2004, he commenced a project entitled Globalization and World Cities (GaWC). The project ranks all major cities of the world based on data that indicates their flow of financial and business activities. According to Taylor et al. (2014), New York and London are consistently ranked on top of the list, occupying Alpha ++ world city status. The second-tier status, Alpha +, includes Tokyo, Hong Kong, Paris, Singapore, Shanghai, Beijing, Sydney and Dubai. It is interesting to note that the majority of Alpha + cities come from the Asia-Pacific region. With these cities supporting advanced service needs in the Asia-Pacific, such findings suggest that the region is highly integrated in the global economic network (Taylor et al., 2014).

This article looks more specifically at cities and city-networks in the AsiaPacific region. In particular, it further focuses on investigating the environmental policies of Tokyo. The examination of Tokyo serves as a representative casestudy to understand how global cities could play a role in addressing today's most pressing challenges. The case of Tokyo is chosen for various reasons. First, according to both Sassen (1991) and Taylor et al. (2014), Tokyo is widely considered to be a global city highly integrated into the international economic network. Second, the study of Tokyo could shed light on the role of cities in global governance when national efforts are inadequate or lacking. Despite having hosted the Kyoto negotiations, Japan refrained from setting new reduction targets for the Kyoto Protocol's second commitment period. Nonetheless, this national decision did not hinder Tokyo's climate effort. The city most notably launched the Asian continent's first carbon cap-and-trade programme in 2010. Thus, the study of Tokyo could show the multilevel dynamics under the wider 
context of global environmental governance, which will highlight the interplay between regulation attempts at the international, national, and local level.

\section{Tokyo's contributions to implementing the Kyoto Protocol}

The Kyoto Protocol, understood to be the cornerstone of the global carbon reduction architecture, consists of three initiatives which aim to address the issues of climate change mitigation and adaptation. These include emissions trading (also known as carbon trading), clean development mechanism (CDM), and joint implementation. CDM and joint implementation allow for countries to generate certified emission reduction units (ERU) which could then be traded and used to meet reduction targets. Since the introduction of the three initiatives, carbon trading has attracted the highest degree of interest from scholars and policymakers. Economists were particularly keen to understand how the trading mechanism of immaterial item (i.e., ERU) could be implemented effectively. While the majority of interested parties tracked the development from an economic perspective, the focus has exceedingly emphasised the role of states and overlooked the involvement of sub-state authorities.

Calculation for carbon emissions is not a straightforward task. While the principle of applying measurement, reporting and verification (MRV) was discussed as early as in 2007 at COP13 in Bali (United Nations Climate Change, 2018). In 2014, the governance architecture was still seeking to standardise methods of measuring, reporting and verifying (MRV). Considering the difficulties in assessing reliable data, the national level may not be the most appropriate governance level to introduce carbon trading. After all, national calculation heavily depends on reporting of reduction percentage submitted from lower level of governing units.

\section{The world's first urban carbon trading programme: Tokyo's cap- and-trade scheme}

As a matter of fact, the first carbon-trading programme in Japan and in Asia was launched by the Tokyo Metropolitan Government (TMG). Based on a revised version of the Tokyo Metropolitan Environmental Security Ordinance in June 2008, the TMG introduced the first cap-and-trade in 2010 in an effort to curb carbon emissions. The programme was not only the first carbon trading programme in Asia 
but was also the first urban trading programme in the world (TMG, 2010, p. 48). The launch of the programme has huge implications for future development of the carbon market in Japan and Asia. As the first cap-and-trade system in the region, it has the potential to serve as a blueprint for developing the Japanese national carbon market. Tokyo, in this case, functioned as a site of policy experimentation, where pilot projects colud be tested, perfected and then diffused in a bottom-up manner to the national and even the international level.

The cap-and-trade programme came after earlier policy experimentation of a voluntary reduction scheme that failed to effectively achieve the reduction objective. Koji Miyazawa, Director of Emissions Trading from the Tokyo Government, observed that voluntary reduction became exceedingly difficult (Allianz Knowledge, 2010). On top of carbon trading and other voluntary measures, the city also considered other carbon reduction programmes, such as enhancing energy efficiency in its public transport. However, Miyazawa contends that Tokyo's public transport system already upheld a high standard of energy efficiency. As a result, introduction of a carbon trading mechanism was considered the preferred policy (Allianz Knowledge, 2010). The Tokyo capand-trade programme was introduced after learning from previously launched foreign trading system, namely, the EU Emissions Trading Scheme, or EU ETS (Allianz Knowledge, 2010). After studying the EU's model, Tokyo learned that in its early days the EU ETS lacked an energy reporting system, which was found to be essential for the carbon market to function; thus, the Tokyo programme then ensured that a verification mechanism is in place and that energy usage data is submitted and checked by a third party (Allianz Knowledge, 2010).

Based on studies and evaluation of the EU ETS, the Tokyo Metropolitan Government decided to introduce a compliance period of five years, instead of one. The programme first targeted facilities that consume fuel, heat, electricity more than $1,500 \mathrm{kl}$ a year in crude oil, including universities, hospitals, office buildings, and factories. (TMG, 2010, p. 48) Over one thousand facilities were included in the first phase. Together these facilities were responsible for around $20 \%$ of the city's carbon emissions. (Allianz Knowledge, 2010) In the first compliance period from 2010 to 2014 , buildings in the programme were required to reduce emissions by $8 \%$, and factories by $6 \%$. If the targeted facilities failed to meet the reduction targets, they would be penalised to make further cuts in the second compliance period at 1.3 times the shortfall. (Allianz Knowledge, 2010) During the first compliance period, successful carbon reduction generates carbon credits, which could then be used later in the second compliance phase. Carbon credits were not lendable, thus at the time, Tokyo authorities also considered introducing auctions for allowance credits during the second 
compliance period. The reduction target for the second compliance period was much more ambitious: targeted facilities were expected to collectively reduce emissions by $17 \%$. This reduction objective reflects the overall goal of cutting $25 \%$ of GHG emission in the city by 2020 in comparison to the 2000 level (Allianz Knowledge, 2010).

\section{Global cities: sites of learning, experimentation and knowledge diffusion}

The introduction of the cap-and-trade programme created the opportunity to experiment and address various technical concerns in implementing urban carbon reduction initiatives. Global cities like Tokyo enjoy extensive connections with the outside world, allowing them to obtain knowledge from similar programmes that are already implemented elsewhere. Tokyo also possesses the requisite infrastructure and personnel support to efficiently manage the pilot project of the cap-and-trade programme. The city's robust bureaucratic structure allows it to closely monitor compliance, as well as to identify means of improvement of the programme. Tokyo then serves as a site where new policy is tested before it is introduced nationwide. With their experience and knowledge, cities like Tokyo are in a more informed position to give policy advice to national authorities.

Facilitated by its extensive network ties that reach far beyond Asia, Tokyo serves as a prominent example, which demonstrates the potential of city-to-city, as well as city-to-state policy diffusion.

According to Sassen (1991), cities are hubs where extensive flows of information, services, goods and capital occur. In the age of information and globalisation, cities do not respond to global challenges in isolation. Rather, they form links with other cities that face similar challenges and seek to address the problem in city-networks. In the case of Tokyo, the city has entered numerous city-networks that enable regular city-to-city exchanges. Most prominently, Tokyo is part of the international city-network of C40 - Cities Climate Leadership Groupalong with other major global cities such as London, Hong Kong, Shanghai, Seoul, and Los Angeles. Since the launch of Tokyo's cap-and-trade programme in 2010, other cities in the network have expressed interest in learning from Tokyo. The proceedings of an international workshop of $\mathrm{C} 40$ cities in East Asia show that the Tokyo cap-and-trade project was discussed in detail and shared with other cities like Shanghai, which later followed Tokyo's example and launched its own cap-and-trade scheme (The World Bank, 2013). 


\section{Overcoming divergence of national interests at the international level: filling the governance gap}

The relevance of cities and local governments in addressing global problems have long been systematically overlooked in IR literature. The above case suggests that policy change and diffusion lie at the local, rather than at the national level. This is due to the divergence of national interests at international negotiations. It is a known fact that agreement for universal legally binding treaties requires tremendous effort. The international community in general is disappointed at the pace of the negotiation process of the UNFCCC, where the interests and priorities between individual states, and between developed and developing countries, become exceedingly difficult to reconcile.

The much anticipated Copenhagen Summit ended without conclusion of any binding quotas (Lynas, 2009). China, while considered a key player in the fight against climate change, has for a long time been criticised for holding back progress at the negotiation table (Lynas, 2009). Known for prioritising their domestic need for economic growth over other global concerns, China, along with other major carbon emitters, appeared slow to commit to binding international reduction quotas. States that originally adopted a favourable stance towards the Kyoto Protocol, namely, Canada, Japan, Russia and New Zealand, all decided to withdraw their commitments when they failed to sufficiently reduce GHG emissions. Nevertheless, at the city level, progressive carbon reduction efforts persist and grew broader in scale. In China, pilot carbon trading projects were being introduced in Shenzhen, Beijing, Shanghai, Guangdong, Tianjin, Chongqing, and Hubei. The rollout of large-scale carbon trading programmes across major Chinese cities in the early 2010 have occurred despite a conservative national climate policy. This highlights the potential of cities in filling the governance gap. In this case, cities serve to supplement states' effort in tackling climate issues.

\section{Diffusion of knowledge, ideas and policy through city-networks}

Once the competence of cities in addressing global problems is established, one can identify a wide array of measures already employed by cities in contributing to global environmental governance. Recent development shows that cities are becoming increasingly active in city-networks - a voluntary, flexible and non-hierarchical form of exchange that allows cities to share knowledge and 
experience (Chiu, 2011; 2014; Keck \& Sikkink, 1998). Reports of Tokyo's international activities show that Tokyo participates in numerous city-networks (TMG, 2010). In addition to the network of C40 mentioned above, Tokyo also took a leading role in the Asian Network of Major Cities (ANMC). The network, launched in 2001, has its headquarters in Tokyo. It was formed with the objective of facilitating and promoting co-operation between Asian cities in the area of crisis management, environmental countermeasures and industrial development.

The inclusive and flexible membership policy of city-networks enables cities to engage in knowledge transfer and best practice exchange on a regular basis. It creates an institutionalised channel of communication between cities, facilitating diffusion of ideas and policy. In the network of C40, it is evident that member cities examine and explore possible measures from their network peers when devising new carbon reduction policies. For example, the White Paper produced by TMG extensively studied concrete policies introduced in other C40 cities. These include the imposition of congestion charges in London city centre, exclusive median bus lanes created to supplement other means of public transport in Seoul, priority to one-way driving in Los Angeles, and a parking space levy in Sydney. These studies, enabled by Tokyo's network connections with various C40 network members, contributed new ideas for consideration during the period of policy consultation. It allows Tokyo to make informed decisions in adopting appropriate measures based on evaluating the best practices and the previous experience of cities that face similar urban problems (TMG, 2010).

As noted above, inter-state negotiation is a long and complex process. National representatives are obligated to prioritise national interests. As a result, an international policy acceptable to all parties requires time and efforts to develop. On the other hand, city-to-city exchanges are more flexible, and in turn serve to facilitate more direct city-to-city policy diffusion. As the opening remarks of the report of the 9th Plenary Meeting of the ANMC declared, exchange between Asian cities "is much more flexible than state-level negotiations" and allow member cities to "pursue tangible discussions" (ANMC, 2010, p. 8). This highlights the fact that global environmental governance does not stop at the global level when international agreements cannot be reached, nor at the national level when central governments have other more pressing economic and political concerns. Global environmental governance extends to include policies implemented by local authorities, as well as joint efforts facilitated by city-networks. In this sense, city-networks could bypass the inherent difficulty in introducing progressive climate policy at the international or the national level, and directly allow effective city-to-city policy diffusion. 


\section{The role of global cities in city-networks}

The above paragraphs examined the role of city-networks in facilitating policy and best practices diffusion, as well as exchange of information and experience. This section further asserts that global cities, in particular, are essential actors in maintaining city-networks. Through connecting cities from diverse background across the globe, city-networks emerged as an increasingly influential actor under the larger framework of global governance. It has already been established that local authorities and cities possess the relevant competence in legislating and implementing climate policy (Betsill \& Harriet, 2003; 2004; 2006). However, global cities - defined as cities with a high level of connectivity with the global world - further stand out as main drivers of policy innovation and diffusion. Situated at the core of the global economy, global cities provide the necessary services, human and financial capital to maintain regular exchanges of citynetworks (Sassen, 1991).

First, interviews with TMG officials reveal the importance of an efficient bureaucratic force. Exchanges with foreign cities require staff with the necessary language competence. This may appear a trivial detail. However, with comparatively limited transaction of information, financial and human capital, smaller cities are less connected to the international economy and may find that multilingual staff and services are less readily available. Global cities, on the contrary, have the advantage of having a readily available multilingual labour force to serve specific needs. Consider cases of many smaller towns, where the elected mayor could very often face a limited budget, and shoulder the heavy workload of running an office with a support staff of one. This means that the mayor may be tasked with both clerical and financial responsibilities. The mayor could be the secretary, the accountant and technician in his/ her office. In such localities, not only is multilingual staff difficult and expensive to hire, it may also be financially challenging to maintain multilingual staff to engage in regular exchanges with their foreign counterparts.

Second, global cities are hubs that witness regular and sizable capital transactions. As such, global cities generally possess more resources for maintaining a robust bureaucracy. One of the largest expenses in running international organisations such as the UN and the EU is maintaining the translation operation and a dedicated multilingual administration (Owen, 2005). Active city-network activities can only be ensured by dedicated multilingual staff. Despite the advances of technology, real-time discussions remain the preferred means of communication for important issues. For example, interviews with Tokyo 
officials reveal that scheduling real-time conference calls is one of the major challenges in the day-to-day functions of C40. Member cities of C40 can be found across the globe in different time zones, making it extremely difficult to arrange a mutually acceptable time for real-time discussion. To accommodate the time differences, it has been noted that weekly $\mathrm{C} 40$ conference calls have to be conducted in the evening in Tokyo. Hence, additional time and commitments from staff are required in order to ensure the full participation of members from across the globe, including those located in the Americas and the Pacific. These kinds of activities thus incur cost and create a burden on human resources, and arguably bar active participation of cities that do not enjoy the luxury of maintaining such bureaucratic institutions (Interview with TMG Official, 2011).

\section{Conclusion}

This contribution argues that cities are relevant, if not often overlooked, actors in global environmental governance. Not only do cities launch individual initiatives in fighting against climate change, they also engage in network exchanges with other cities to share their knowledge and experience in curbing GHG emissions. Furthermore, the position of global cities in today's world economy facilitates the transfer of ideas, information and technology. Global cities' advantageous concentration of human and financial capital allow the maintenance of an effective bureaucracy. The flow of services, capital and human resources that are channelled through global cities serve to empower these cities to lead policy experimentation in the area of climate change. The bureaucratic structure and resources provided by global cities ensure effective implementation of innovative projects like Tokyo's cap-and-trade programme. Technical focus on directly addressing global challenges allows cities to overcome the political deadlock that can occur at intergovernmental fora. With cities becoming increasingly involved in city-networks, policy diffusion no longer follows a conventional top-down model. Instead, policy can now bypass national authorities and become diffused directly between cities. Successful pilot projects can also serve as models for introduction at the national and international level. Tokyo is a particularly prominent example of this. To date, the TMG has proposed a national model of carbon trading based on its own cap-and-trade programme. As the first programme of its kind in the Asia-Pacific region, Tokyo also has the ambition to link its own cap-and-trade programme to the international carbon market in the future (TMG, 2010, p. 49). Finally, in 2014, the International Council for Local Environmental Initiatives (ICLEI) was developing a common 
methodology in measuring, reporting and verifying (MRV) GHG emissions in partnership with the C40 (Chiu, 2014). Should such a collaboration found to succeed in standardising MRV methods, it will serve once again to demonstrate the influence and relevance of cities in the global fight against climate change.

Dr. Nikita Chiu is an Ad Astra distinguished fellow in Robotic and Outer Space Governance at Space Engineering Research Center, USC Viterbi School of Engineering. She is the former research fellow in Robotics at the Department of Politics and International Relations at the University of Oxford and was the 2015 AUKLASTA fellow at Tallinn University of Technology.

\section{References}

Allianz Knowledge (2010), 'Interview with Koji Miyazawa,' Open Knowledge. Retrieved from http://knowledge.allianz.com/environment/pollution/?586/japanscap-and-trade-program-for-carbon-emissions [accessed 5 October 2014]

ANMC (2010), Report of the 9th plenary meeting in Tokyo, Asian Network of Major Cities 21 (ANMC21), Tokyo Metropolitan Government.

Arsenault, C. (2012), 'Kyoto extension flounders at climate talks,' Al Jazeera, 27 November. Retrieved from http://www.aljazeera.com/news/2012/11/2012112 7171525607911.html [accessed 10 Sep 2014]

Betsill, M. M. \& Bulkeley, H. (2003), Cities and Climate Change: Urban Sustainability and Global Environmental Governance, London: Routledge.

Betsill, M. M. \& Bulkeley, H. (2004), 'Transnational networks and global environmental governance: The cities for climate protection program,' International Studies Quarterly, vol. 48, no. 2, pp. 471-493. https://doi.org/10.1111/j.00208833.2004.00310.x

Betsill, M. M. \& Bulkeley, H. (2006), 'Cities and the multilevel governance of global climate change,' Global Governance: A Review of Multilateralism and International Organizations, vol. 12, no. 2, pp. 141-159.

https://doi.org/10.1163/19426720-01202004

Carrington, D. \& Vaughan, A. (2011), 'Canada condemned at home and abroad for pulling out of Kyoto treaty,' The Guardian, 13 December. Retrieved from http:// www.theguardian.com/environment/2011/dec/13/canada-condemned-kyotoclimate-treaty [accessed 30 Sep 2015]

Chiu, N. (2011), 'Networked cities' responses to global problems: a typology,' JCP: Journal of Comparative Politics, vol. 4, no. 2, pp. 111-125. 
Chiu, N. (2014), Mayoral Orders: City-Networks in the New Age of Global Governance, $\mathrm{PhD}$ thesis, The Graduate Institute, Geneva.

Karaki, R. (2011), Interview with Ryouko Karaki, co-ordinator for C40, International Cooperation Section, Bureau of Environment, Tokyo Metropolitan Government, Tokyo, Japan, 6 December.

Keck, M. E. \& Sikkink, K. (1998), Activists beyond Borders: Advocacy Networks in International Politics, Ithaca, NY: Cornell University Press.

Lynas, M. (2009), 'How do I know China wrecked the Copenhagen deal? I was in the room,' The Guardian, 22 December.

Mooney, C. (2018), 'Trump can't actually exit the Paris deal until the day after the 2020 election. That's a big deal,' The Washington Post, 12 December.

Owen, J. (2005), 'With 20 official languages, is EU lost in translation?' National Geographic News, 22 February. Retrieved from http://news.nationalgeographic. com/news/2005/02/0222_050222_translation.html [accessed 28 Sep 2014]

Ruggie, J. G. (2001), 'global_governance. net: The global compact as learning network,' Global Governance, vol. 7, pp. 371-378. https://doi.org/10.1163/1942672000704003

Sassen, S. (1991), The Global City: New York, London, Tokyo, Princeton \& Oxford: Princeton University Press.

Taylor, P. J. et al. (2014), The World According to GaWC 2004. Retrieved from http:// www.lboro.ac.uk/gawc/gawcworlds.html [accessed 15 Sep 2014]

The World Bank (2013), Proceedings of the International Workshop on Best Practice of Climate Change Action Plan of C40 Cities in East Asia. Retrieved from https:// www.clc.gov.sg/docs/default-source/reports/proceedings-of-the-internationalworkshop.pdf [accessed 21 Oct 2019]

Tokyo Metropolitan Government (2010), Environment White Paper 2010, Tokyo Environmental Policy Section, Tokyo, Japan.

United Nations Climate Change (2018), 'International consultation and analysis for non- Annex I Parties.’ Retrieved from https://unfccc.int/process/transparency-andreporting/reporting-and-review-under-the-convention/biennial-update-reportsand-international-consultation-and-analysis-non-annex- i-parties/internationalconsultation-and-analysis-for-non-annex-i-parties [accessed 31 Mar 2018]

US Conference of Mayors Climate Protection Agreement (2008), Washington, DC: The US Conference of Mayors. 